\title{
Kinetic, Thermodynamic and Isotherm Studies for the Removal of Acid Red 88 from Aqueous Medium by Polyaniline- $\mathrm{CuCl}_{2}$ Composite
}

\section{ANUSHA DHANAGOPAL, LINGESWARI DHEENATHAYALAN and VIMALA THIYAGARAJAN*}

Department of Chemistry, Seethalakshmi Ramaswami College, Affiliated to Bharathidasan University, Tiruchirappalli-620002, TamilNadu, India.

*Corresponding author E-mail: vimalsrc@gmail.com

http://dx.doi.org/10.13005/ojc/350621

(Received: October 30, 2019; Accepted: December 07, 2019)

\begin{abstract}
The metal salt doped polyaniline has been used as adsorbent for the removal of synthetic dye. The influence of experimental parameters like association time, adsorbent dosage, agitating speed, $\mathrm{pH}$ and electrical conductivity on adsorption of Acid Red 88 was systematically investigated. More than $95 \%$ of Acid Red 88 was removed after $55 \mathrm{~min}$ of adsorbent/adsorbate contact time for $0.3 \mathrm{~g} / \mathrm{L}$

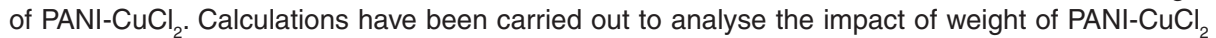
composite and concentration of Acid Red 88 on the percentage of decolourisation. Kinetics and isotherm analysis were also carried out to describe the adsorption process. Electrical conductivity, SEM and FTIR technique were used to characterize the adsorbent before and after adsorption. The thermodynamic parameters like changes in free energy, enthalpy and entropy were also evolved to predict the nature of adsorption. The adsorbent is stable, easy to prepare and suitable to remove Acid Red 88 from effluent.
\end{abstract}

Keywords: Polyaniline, Synthetic dye, Adsorption, Isotherms, Kinetics and Thermodynamics.

\section{INTRODUCTION}

Water is a life saving compound which is vital for all living plants and animals. The use of water has increased many folds due to development of technology and population explosion which causes the pollution of water. Chemical industries present nearby water resources pollute rivers, lakes and underground water. Water pollution brings detrimental effect to the human population, aquatic life and plant kingdom. City sewage, effluent from industries like tannery, dyeing units, and metallurgical processes are mixed into the aquatic sources and contaminate the water. Synthetic dyes are chemically and photolytically fast which are extremely persisting in natural environments. Textile industry is a foremost one in staining the water which causes BOD, COD and eutrophication of water. Micro toxicity of water affects the biotic communities. ${ }^{1}$ Development of treatment methods and continuous search for the best process is ongoing. Adsorption is one of the economically viable and operationally simple method for the treatment of dye effluent.

This is an Open Access article licensed under a Creative Commons license: Attribution 4.0 International (CC- BY). Published by Oriental Scientific Publishing Company @ 2018 
Polyaniline exhibits wide varieties of applications in the field of photosensitizers, ${ }^{2}$ sensor, ${ }^{3}$ adsorption, ${ }^{4-6}$ solar cells etc. The present study is an attempt to remove Acid Red 88 (AR 88) from aqueous solution by using PANI-CuCl${ }_{2}$ as adsorbent.

\section{MATERIALS AND METHODS}

\section{Materials}

Acid Red 88 was procured from EMCO Dye Stuff Pvt. Ltd., Maharashtra. Dye was used as received. Aniline and $\mathrm{HCl}$ were obtained from Merck Specialities $(\mathrm{P})$ Ltd., Mumbai. Ammonium persulphate was obtained from Loba Chemie PVT. LTD., Mumbai. $\mathrm{CuCl}_{2}$ was obtained from E.Merck (India) LTD., Mumbai. Structure and details of the dye is shown in the Fig. 1 and Table 1.

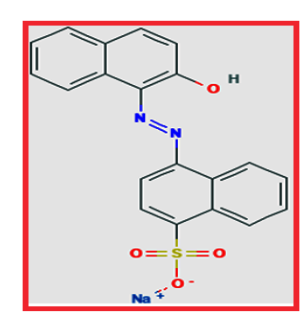

Fig.1. Structure of Acid Red 88
Table 1: Properties of AR 88

\begin{tabular}{cc}
\hline Molecular formula & $\mathrm{C}_{20} \mathrm{H}_{13} \mathrm{~N}_{2} \mathrm{NaO}_{4} \mathrm{~S}$ \\
\hline Molar mass & $400.38 \mathrm{~g} / \mathrm{mol}$ \\
CAS number & 23621588 \\
PubChem & 135465069 \\
ChemSpider & 10483346 \\
$\lambda_{\max }$ & $518 \mathrm{~nm}$ \\
\hline
\end{tabular}

\section{Instrumentation}

Batch adsorption studies were carried out in presence of UV light of 6 ampere using RIS-24 BL orbital shaker. The concentration of dye solutions were measured using MAPADA V-1100 D spectrophotometer. Four Probe Setup DFP-03 was used for finding electrical conductivity. Equip-Tronics $\mathrm{pH}$ meter was used to measure $\mathrm{pH}$.

\section{Methods}

\section{Preparation of PANI-CuCl}

Copperchloride doped polyaniline was synthesized by chemical oxidation coupled with polymerization, where ammonium persulphate was used as an oxidant ${ }^{7} .10 \mathrm{~g}$ of ammonium persulphate dissolved in $20 \mathrm{~mL}$ distilled water was added into the solution of aniline $(5 \mathrm{~mL})$ dissolved in $1.5 \mathrm{M} \mathrm{HCl}$ $(70 \mathrm{~mL})$. To that aliquot $5 \mathrm{~mL}$ of $8 \% \mathrm{CuCl}_{2}$ was added. The solution mixture was stirred at 400rpm for $5 \mathrm{~h}$ at room temperature. After the polymerization PANI$\mathrm{CuCl}_{2}$ granules was obtained.

\section{Preparation and Standardization of Dye Solution}

Stock solution of Acid red 88 was prepared in distilled water ( $1 \mathrm{~g} / \mathrm{L})$. Acid red 88 was standardized by measuring the optical densities of various concentrations of the dye solution at $518 \mathrm{~nm}$ using visible spectrophotometer.

\section{Adsorption Studies}

The effect of significant parameters on the rate of adsorption like contact time, concentration of the dye solution (9 to $21 \mathrm{mg} / \mathrm{L}$ ), $\mathrm{pH}(4-9)$, adsorbent dosage (0.1 to $0.7 \mathrm{~g} / \mathrm{L})$, agitation speed (100-250) and temperature (303-318 K) were analysed for the adsorption of AR 88. Appropriate quanitity of PANI$\mathrm{CuCl}_{2}$ composite and acid red 88 are mixed to $100 \mathrm{~mL}$ in water in a $250 \mathrm{~mL}$ beaker. The mixture was agitated at $250 \mathrm{rpm}$ in orbital shaker at $30^{\circ} \mathrm{C}$. Concentration of unadsorbed dye was measured using UV-Vis spectrophotometer at $518 \mathrm{~nm}$. Equilibrium quantity of AR 88 was measured using the formula.

$q_{e}=\frac{\left(C_{o}-C_{e}\right) V}{W}$

$\%$ Decolourisation $=\frac{\left(C_{0}-C_{t}\right)}{C_{0}} X 100$

$\mathrm{C}_{0}$ the dye initial concentration

$\mathrm{C}_{\mathrm{t}}(\mathrm{mg} / \mathrm{L})$ concentration of AR 88 at different time interval $t$ (minute)

$\mathrm{q}_{\mathrm{e}}(\mathrm{mg} / \mathrm{g})$ - quantity of AR88 adsorbed per unit mass of the adsorbent at equilibrium,

$\mathrm{W}(\mathrm{g})$ is the amount of adsorbent used.

Desorption

\section{RESULTS AND DISCUSSION}

The influence of contact time on the batch adsorption of dye was carried out at $30^{\circ} \mathrm{C}$. Removal of AR 88 on PANI composite was rapid in the initial stage, the quantity of dye adsorbed gradually increased, afterwards and then no change in amount adsorbed which indicate that the equilibrium reached ${ }^{8}$ is shown in Fig. 2. The successive increase in adsorption and attainment of equilibrium state was obtained at $55 \mathrm{~min}$ for (AR 88), because of the limited mass transfer of dyes from the bulk solution to the external surface of the adsorbent. 


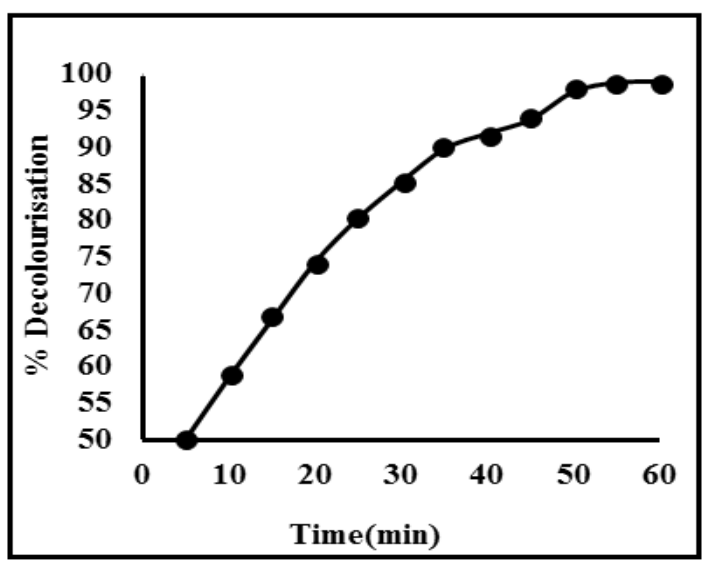

Fig. 2. Effect of contact time on Acid Red 88

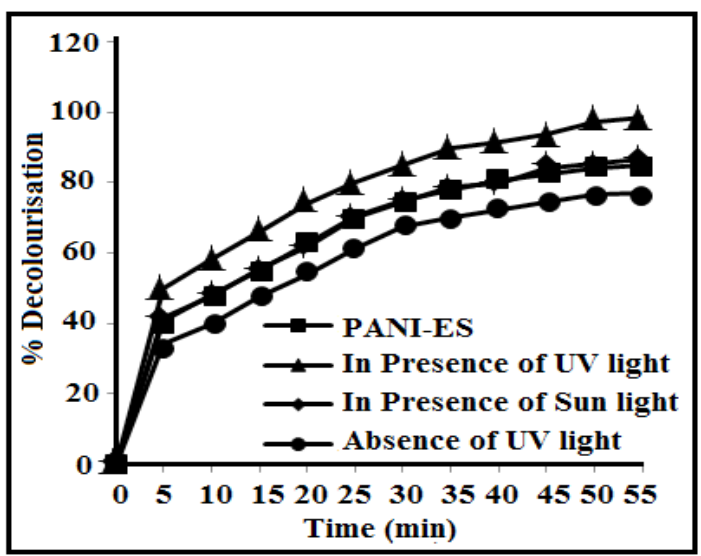

Fig. 3. Comparison of Efficiency of $8 \% \mathrm{PANI}^{-\mathrm{CuCl}_{2}}$

Efficiency of $8 \%$ PANI-CuCl ${ }_{2}$ composite and PANI-ES compared under similar condition for the removal AR 88 which reveal that $\mathrm{CuCl}_{2}$ doped PANI has higher efficiency than PANI-ES. The adsorption study is carried out in the presence and absence of UV light illustrated that UV light assisted the rate of decolourisation under similar condition. The adsorption study is carried out by exposing the reaction aliquot to sunlight alone, remove the dye at a slower rate but complete removal is possible is shown in Fig. 3. AR 88 is not decolourised under any of the above conditions without addition of adsorbent.

The effect of variation in initial dye concentration on the removal of AR 88 by PANI$\mathrm{CuCl}_{2}$ was investigated at different concentration ranges from 9 to $21 \mathrm{mg} / \mathrm{L}$ (AR 88). The percentage removal of dye is increased with decrease in initial dye concentration whereas the $q_{e}$ increases with increase in initial dye concentration and the time required to reach equilibrium is also increased $d^{9,10}$ is graphically shown in the Fig. 4. At higher initial concentration of dye there may be a strong interaction between PANI-CuCl ${ }_{2}$ composite and dye molecules. But above optimal concentration of dye the active sites required for adsorption is less which may cause the reduction in rate of decolourisation.

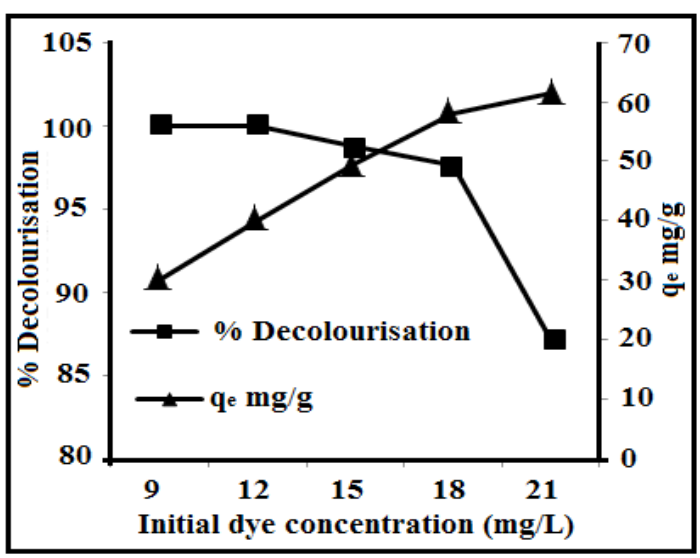

Fig. 4. Effect of Initial Dye Concentration

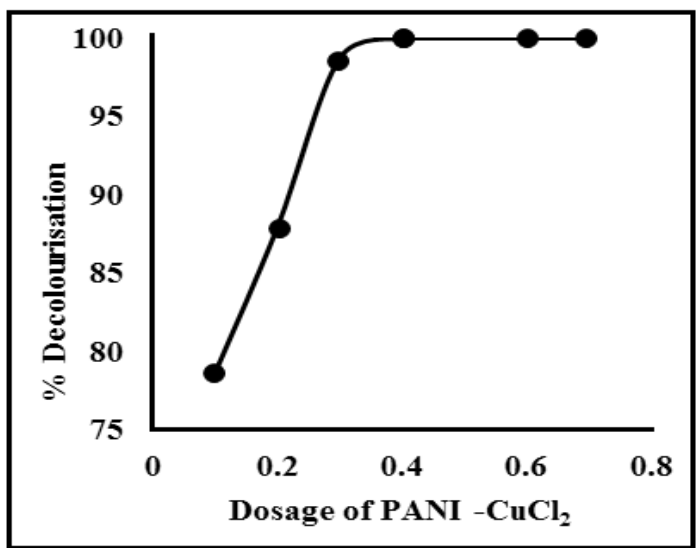

Fig. 5. Effect of Adsorbent Dosage

The amount of PANI-CuCl , used in colour removal process is a vital criterion because it decides the holding power of adsorbent for given dye concentration. The impact of adsorbent dosage was evaluated by changing the amount of PANI- $\mathrm{CuCl}_{2}$ from $0.1 \mathrm{~g} / \mathrm{L}$ to $0.7 \mathrm{~g} / \mathrm{L}$ for Acid Red 88 dye at a concentration of $15 \mathrm{mg} / \mathrm{L}$. Increasing the adsorbent dosage, augment the contact surface of adsorbent particle and enhances the number of sites available for adsorption ${ }^{11}$. Thus, the dose of adsorbent is increased; the higher is the access for adsorbate and increase the chance for adsorption which can be inferred from Figure 5. 
The effect of variation of temperature on adsorption of dyes on $\mathrm{CuCl}_{2}$ doped PANI composites was studied at $30,35,40$ and $45^{\circ} \mathrm{C}$ by keeping dosage of adsorbent, dye concentration, $\mathrm{pH}$ and stirring rate constant. It was indicated that the adsorption equilibrium of all dyes decreased with the increase in temperature (Fig. 6) indicating the exothermic behaviour of adsorption ${ }^{12,13}$. This may be due to an increase in movement of dye molecule, greater aqueous solubility of dyes which reduces the adsorption process and increase in temperature may decrease the electrostatic interaction between the dye molecule and surface of the adsorbent.

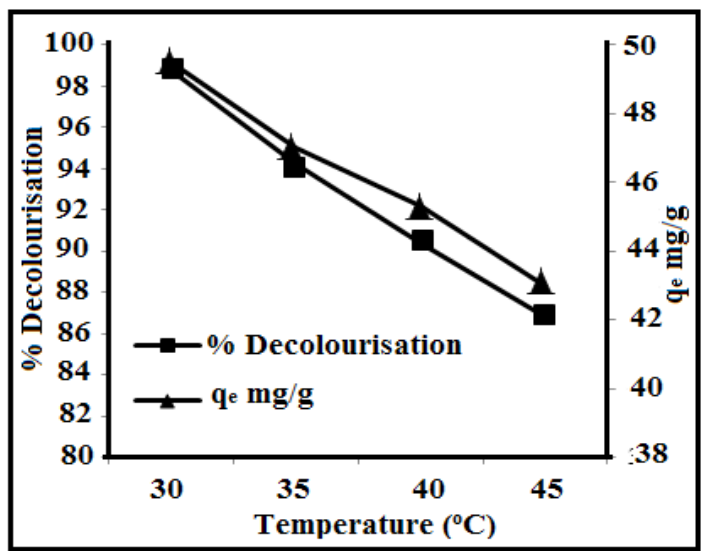

Fig. 6. Effect of Temperature

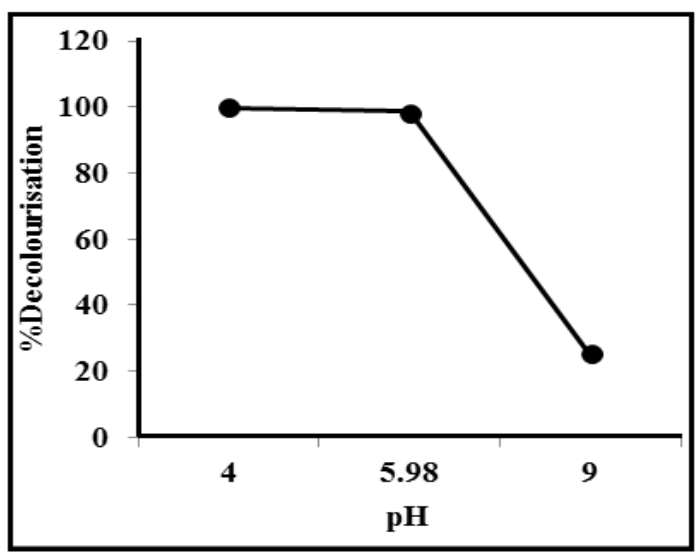

Fig. 7. Effect of pH

The quantity of dye adsorbed was evaluated as a function of $\mathrm{pH}$ in the range 4 to 9 . The $\mathrm{pH}$ of the dye solution was maintained over the range using $0.1 \mathrm{~N} \mathrm{HCl}$ or $0.1 \mathrm{~N} \mathrm{NaOH}$ solution after the addition of adsorbent. Adsorbent dosage, concentration, temperature, stirring rate and volume of dye solution are kept constant to analyse the effect of $\mathrm{pH}$. The plot of percentage removal versus $\mathrm{pH}$ is the Fig. 7 . Effect of $\mathrm{pH}$ provides possible information about the sorbate and sorbent interaction and the dissociated dye anions at acidic $\mathrm{pH}$ attracted by the positively charged adsorbent whereas at alkaline $\mathrm{pH}$ adsorption decreased because the negatively charged PANI EB may repulse the dye molecules ${ }^{14}$.

Increase in round per minute increases the rate of decolourisation and it is approximately twice when the speed increases from 100 RPM to 250 RPM which may be due to reduction of resistance at the boundary of the adsorption of dye molecules by the adsorbent ${ }^{15,16}$. This can be seen in the Figure 8

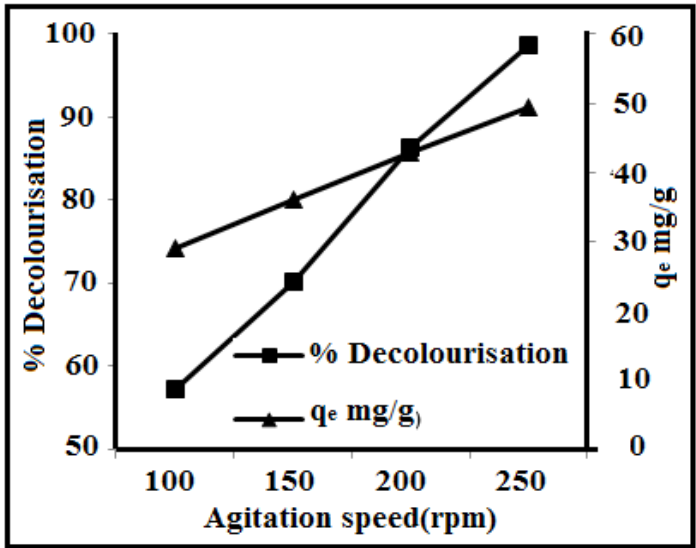

Fig. 8. Variation of Agitation Speed

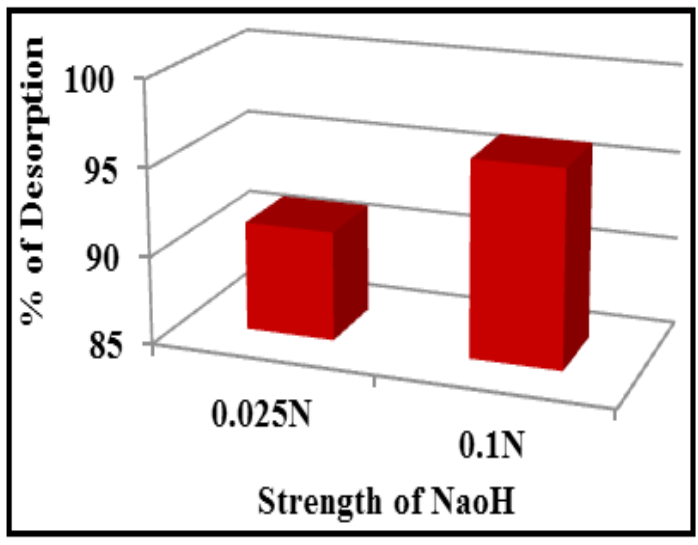

Fig. 9 Percentage of Desorption

The desorption trend of AR 88 at different strength of $\mathrm{NaOH}$ was opposite to that of adsorption process. An increase in the strength of $\mathrm{NaOH}$ solution from 0.025 to $0.1 \mathrm{~N}$ increases desorption efficiency from 91 to $96 \%$. AR 88 is anionic in nature, adsorption of dye in acidic medium and regeneration 
of colour in alkaline medium showed that AR 88 was held by the adsorbent, most probably by ion exchange. Reusability study revealed that the dye is desorbed in $\mathrm{NaOH}$ and reusability is observed and the percentage of dye decolourised is gradually reduced in successive cycles. This also proves the efficiency of PANI-CuCl composite as an effective adsorbent. Fig. 9 and 10 shows the percentage of desorption and percentage of readsorption graphically.

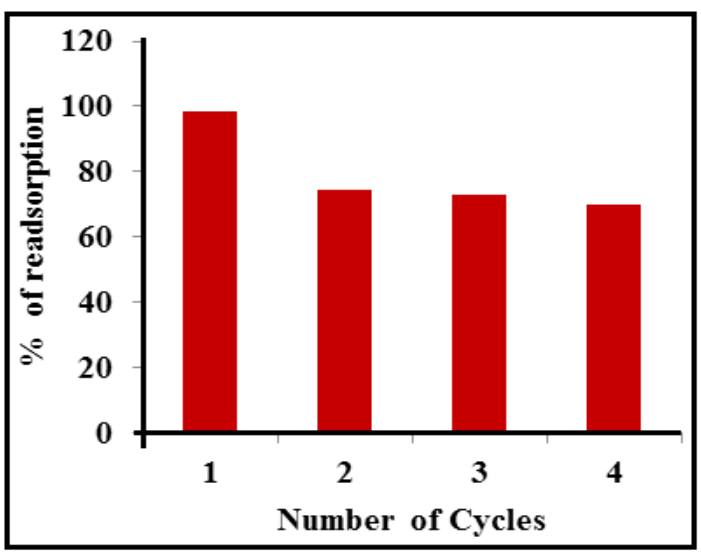

Fig. 10. Percentage of readsorption

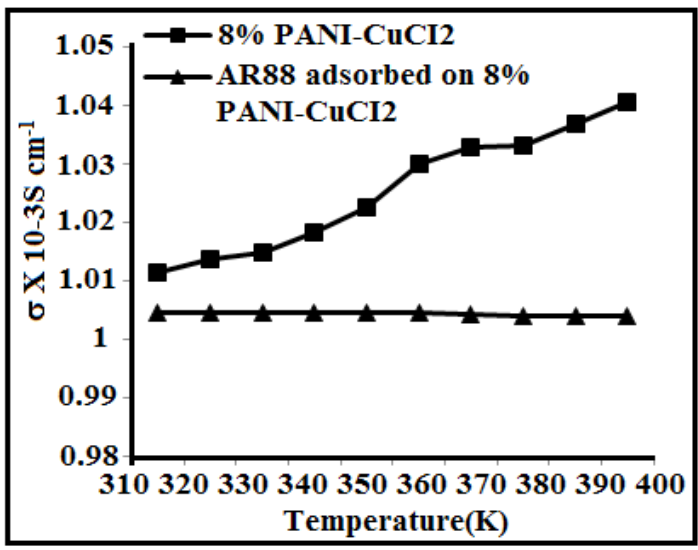

Fig.11. Electrical Conductivity

The electrical conductivity of pristine and dye loaded PANI-CuCl ${ }_{2}$ composite were measured separately and it is found that electrical conductivity of polyaniline- $\mathrm{CuCl}_{2}$ composite is higher than dye adsorbed composites. This imply that the dye accumulated on the superficial area of the polymer composite gives rise to a lean sheet of low doped material because of the removal of the counter ions which leads to drop in electrical conductivity Figure 11.

\section{Isotherm Studies}

The relationship between the amount of a substance adsorbed at constant temperature and its concentration in the equilibrium solution is called the adsorption isotherm.

The linearized form of Langmuir equation is

$\frac{C_{e}}{q_{e}}=\frac{\left(1+b C_{e}\right)}{Q_{\mathrm{o}} b}$

Where $Q_{0} \& b$ are Langmuir constants related to maximum monolayer coverage capacity and $b$ is the constant related to the free energy of adsorption ${ }^{17}$. $R_{L}$ value calculated from the Langmuir equation predict the adsorption is favourable $\left(0<R_{L}<1\right)$.

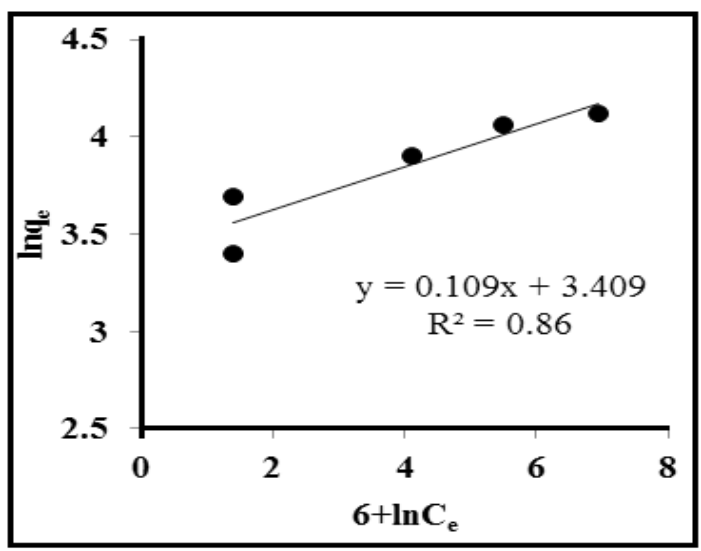

Fig. 12. Langmuir adsorption isotherm

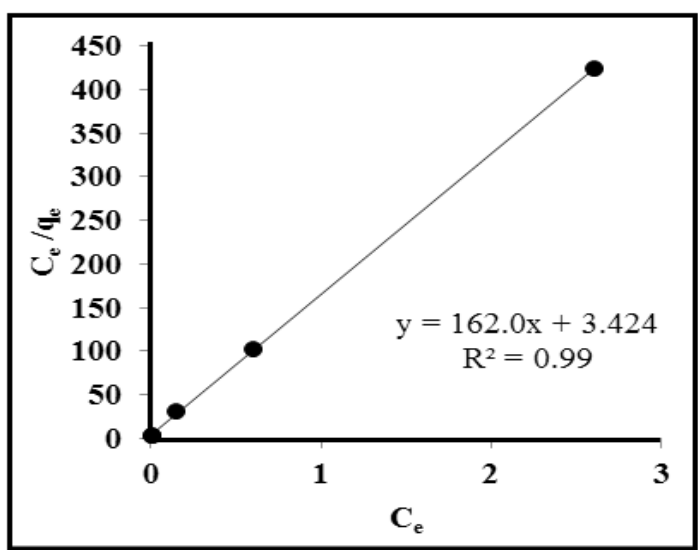

Fig.13. Freundlich adsorption isotherm

The mathematical expression relates the equilibrium of dye solution and heterogeneous surface of the PANI-CuCl is described by Freundlich isotherm. 
The equation can be expressed in its linear form as:

$$
\ln \mathrm{q}_{\mathrm{e}}=\ln \mathrm{K}_{\mathrm{F}}+\frac{1}{n} \ln \mathrm{C}_{\mathrm{e}}
$$

When $\operatorname{lnq}_{\mathrm{e}}$ is plotted against $\ln \mathrm{C}_{\mathrm{e}}$ a straight line with a slope $1 / n$ and intercept $\operatorname{lnK}_{\mathrm{F}}$ as obtained is shown in Fig. 13. The values of Freundlich constant, $n$ is $9.17(1 / n$ is lower than 1$)$ reveals that the surface of the adsorbent is heterogeneous and adsorption occurred spontaneously. The analysed adsorption is favorable adsorption ${ }^{18}$.

Table 3: Isotherm models and their calculated constant values

\begin{tabular}{|c|c|c|c|c|}
\hline Isotherms & Linear form of equation & Plot & $\mathrm{R}^{2}$ value & Calculated values \\
\hline Freundlich & $\operatorname{lnq}=\ln K_{f}+1 / n \operatorname{lnC} e_{e}$ & $\operatorname{lnq} v_{e} \ln C_{e}$ & 0.860 & $\mathrm{n}=9.17 ; \mathrm{K}_{\mathrm{F}}=30.23(\mathrm{~L} / \mathrm{g})$ \\
\hline Langmuir & $C_{e} / q_{e}=\left(1+b C_{e}\right) / Q_{0} b$ & $\mathrm{C}_{\mathrm{e}} / \mathrm{q}_{\mathrm{e}}$ vs $\mathrm{C}_{\mathrm{e}}$ & 0.999 & $Q_{0}=6.17 \mathrm{mg} / \mathrm{g} ; \mathrm{b}=47.17(\mathrm{~L} / \mathrm{mg}) ; R_{\mathrm{L}}=0.001$ \\
\hline Temkin & $q_{e}=B_{T} \ln K_{T}+B_{T} \ln C_{e}$ & $q_{e} v s \ln C_{e}$ & 0.910 & $\mathrm{~B}_{\mathrm{T}}=504.84 \mathrm{KJ} / \mathrm{mol} ; \mathrm{K}_{\mathrm{T}}=298.87 \mathrm{~L} / \mathrm{mg}$ \\
\hline
\end{tabular}

\section{Temkin Isotherm}

Equation (5) represents the Temkin isotherm ${ }^{19}$ and the calculated $B_{T}$ indicates that there is a strong interaction between AR 88 and PANI$\mathrm{CuCl}_{2}$.

$\mathrm{q}_{\mathrm{e}}=\mathrm{B}_{\mathrm{T}} \ln \mathrm{A}_{\mathrm{T}}+\mathrm{B}_{\mathrm{T}} \ln \mathrm{C}_{\mathrm{e}}$

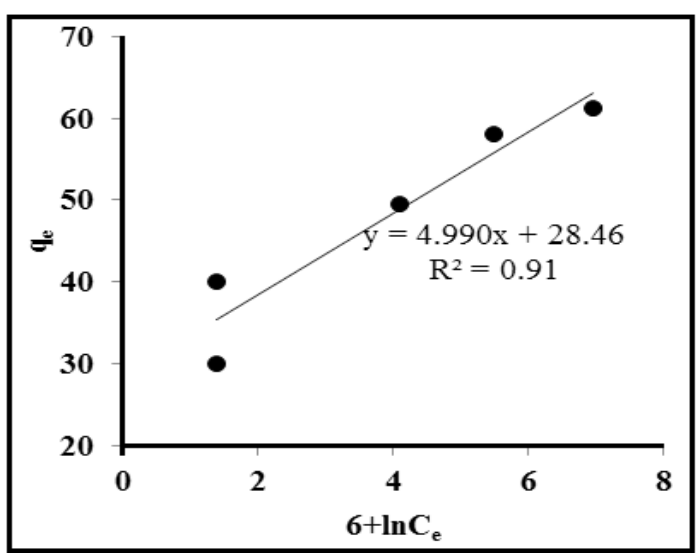

Fig.14. Temkin adsorption isotherm

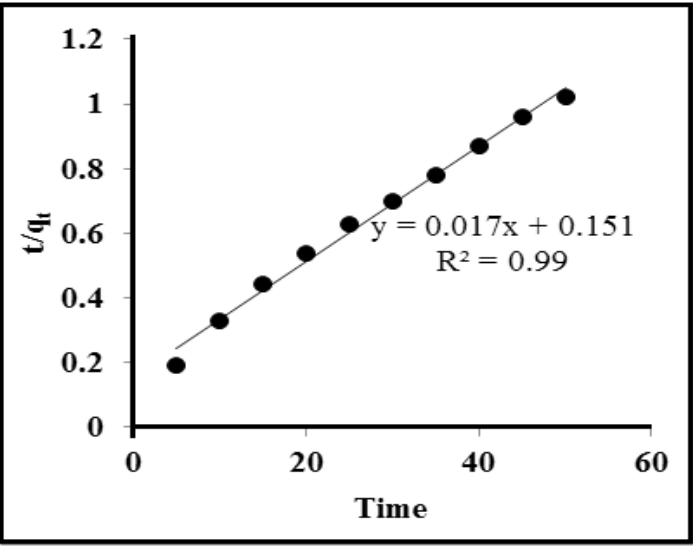

Fig.15. Pseudo-Second-Order-Kinetics

\section{Adsorption Kinetics}

Kinetic aspects of adsorption provide useful data for determining the feasibility of scaleup operations and reliable fact on the mechanism of sorption. The linear form of pseudo second order kinetic equation is,

$$
\frac{t}{q_{t}}=\frac{1}{k_{2} q_{e}^{2}}+\frac{1}{q_{e}} t
$$

The plot of $t / q_{t}$ versus $T$ gave the perfect straight line which is shown in the Fig. 15. From the plot of $t / q_{t}$ versus $T, K_{2}$ and $q_{e}$ are determined. The correlation coefficient $\left(R^{2}\right)$ value is high which shows greater accuracy and this process follows Pseudosecond-order kinetics Table 4.

Table 4: Kinetic Data

\begin{tabular}{lcccc}
\hline Dye & $\begin{array}{c}\mathrm{q}_{\mathrm{e}}(\mathrm{mg} / \mathrm{g}) \\
\text { Experimental }\end{array}$ & $\begin{array}{c}\mathrm{q}_{\mathrm{e}}(\mathrm{mg} / \mathrm{g}) \\
\text { Calculated }\end{array}$ & $\mathrm{K}_{2}$ & $\mathrm{R}^{2}$ \\
\hline AR88 & 49.5 & 58.82 & $1.91 \times 10^{-3}$ & 0.999 \\
\hline
\end{tabular}

\section{Intra Particle Diffusion}

The equation for intraparticle diffusion is expressed as follows,

$q_{t}=K_{i d}(t)^{0.5}+C$

Where $\mathrm{q}_{\mathrm{t}}(\mathrm{mg} / \mathrm{g})$ is the amount of dye ions adsorbed onto $8 \%$ PANI- $\mathrm{CuCl}_{2}$ at $\mathrm{t}$ and $\mathrm{K}_{\text {id }}$ (mg/ (g.min)) is the intra particle diffusion rate constant. As shown in the figure the plot exhibited a break, initial sharp line corresponds to the adsorption of dye to the external surface of PANI-CuCl${ }_{2}$ and the second part of the plot related to the gradual adsorption stage of the interior portion of the adsorbent. 


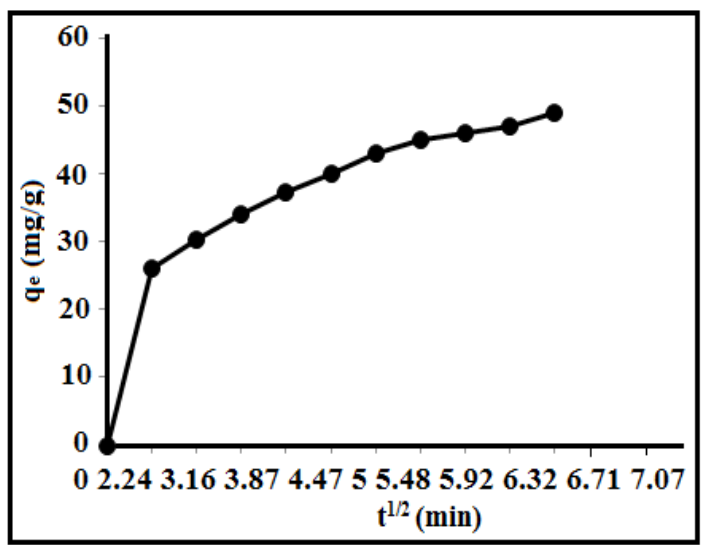

Fig. 16. Intraparticle Diffusion of AR 88

\section{Thermodynamic parameters}

Thermodynamic parameters like changes in Gibbs free energy $\left(\Delta \mathrm{G}^{\circ} \mathrm{KJmol}^{-1}\right)$, enthalpy $\left(\Delta \mathrm{H}^{\circ}\right.$ $\left.\mathrm{KJmol}^{-1}\right)$ and entropy $\left(\Delta \mathrm{S}^{\circ} \mathrm{KJmol}^{-1}\right)$ were calculated using the following equation

$$
\ln \mathrm{K}_{\mathrm{d}}=-\frac{\Delta \mathrm{H}^{\circ}}{R T}+\frac{\Delta \mathrm{S}^{\circ}}{R}
$$

Where $\mathrm{K}_{\mathrm{d}}$ is the equilibrium constant, the values of $\Delta H^{\circ}$ and $\Delta S^{\circ}$ were calculated from the slope and intercept of van't Hoff plots of In $\mathrm{K}_{\mathrm{d}}$ versus $1 / \mathrm{T}$. The $\Delta H^{\circ}$ value for AR 88 calculated from van't Hoff equation is $-115 \mathrm{KJ} \mathrm{mol}^{-1}$. The negative value of $\Delta \mathrm{H}^{\circ}$ indicates that the overall adsorption process was exothermic in nature. The negative value of $\Delta S^{\circ}(-335$ $\mathrm{KJ} \mathrm{mol}^{-1}$ ) shows that there is decrease in disorder of the system, thus we can tell that electrostatic binding between adsorbate and adsorbent in adsorption process.

The value of Gibb's free energy was calculated at four different temperatures according to the equation

$$
\Delta G^{\circ}=-R T \ln K_{L}
$$

The negative value of $\Delta \mathrm{G}^{\circ}$ indicates the spontaneous nature of the adsorption process. The calculated values are given in the Table 5 .

Activation energy is calculated from the Arrhenius equation

$\ln \mathrm{k}=\ln \mathrm{A}-\mathrm{E}_{\mathrm{a}} / \mathrm{RT}$

(Ea) is calculated from the slope of plots of In $\mathrm{k}$ versus $1 / \mathrm{T}$ is found to be $109 \mathrm{KJ} \mathrm{mol}^{-1}$ which also supports adsorption ${ }^{21}$.

Table 5: Calculated thermodynamic parameters and their outcome results

\begin{tabular}{ccc}
\hline $\begin{array}{c}\text { Thermodynamic } \\
\text { parameters }\end{array}$ & $\begin{array}{c}\text { Calculated values } \\
\text { for } \mathrm{AR} 88\end{array}$ & Outcome results \\
\hline$\Delta \mathrm{G}^{\circ}$ & $-6.751 \mathrm{KJ} \mathrm{mol}^{-1}$ & $\begin{array}{c}\text { Spontaneous and } \\
\text { feasible in nature } \\
\end{array}$ \\
& $-6.863 \mathrm{KJ} \mathrm{mol}^{-1}$ & \\
& $-6.974 \mathrm{KJ} \mathrm{mol}^{-1}$ & \\
& $-7.086 \mathrm{KJ} \mathrm{mol}^{-1}$ & \\
$\Delta \mathrm{S}^{\circ}$ & $-335 \mathrm{KJ} \mathrm{mol}^{-1}$ & Associative mechanism \\
$\Delta \mathrm{H}^{\circ}$ & $-115 \mathrm{KJ} \mathrm{mol}^{-1}$ & Exothermic in nature \\
\hline
\end{tabular}

\section{FTIR Analysis}

FTIR spectral analysis of the unloaded $8 \%$ PANI-CuCl ${ }_{2}$ composite shows a characteristic peak at $3434 \mathrm{~cm}^{-1}$ due to the $\mathrm{N}-\mathrm{H}$ stretching vibration which is absent in AR 88 loaded PANI-CuCl ${ }_{2}$ composite. The dye treated polymer composite showed some new peaks and few peaks shifted which can be inferred from Figure (17(a) and 17(b)).

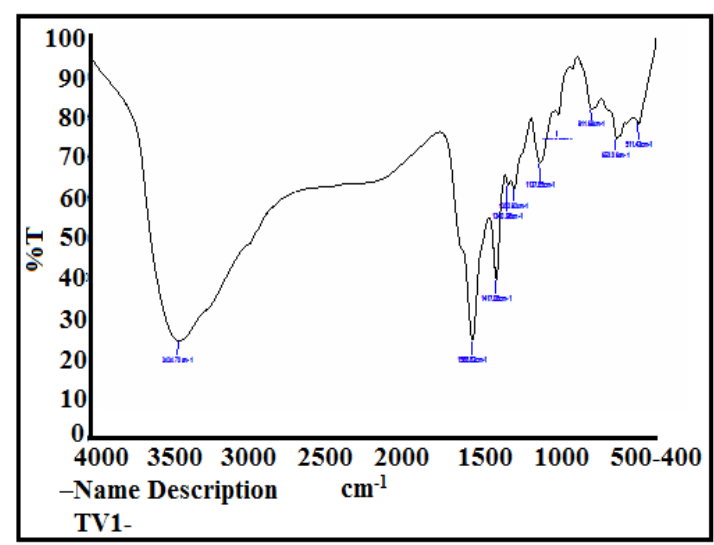

Fig. 17(a) PANI- $\mathrm{CuCl}_{2}$ Before Adsorption

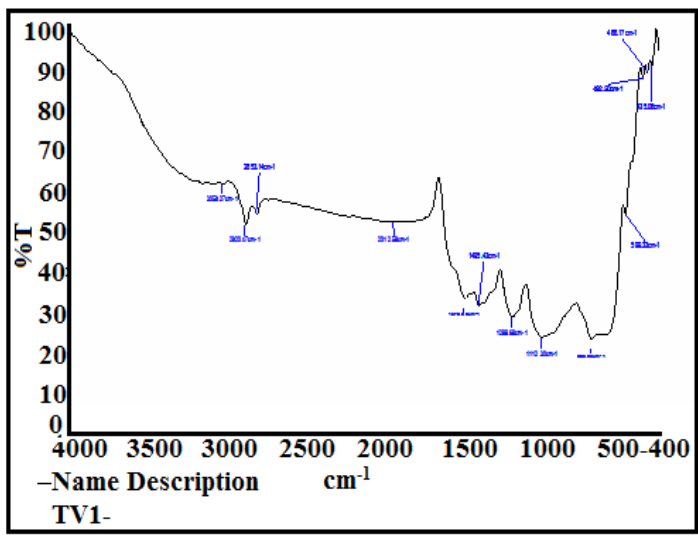

Fig. 17(b) PANI- $\mathrm{CuCl}_{2}$ After Adsorption of AR 88 


\section{Scanning Electron Microscopy}

Recorded SEM images of PANI-CuCl composite before and after adsorption of AR 88

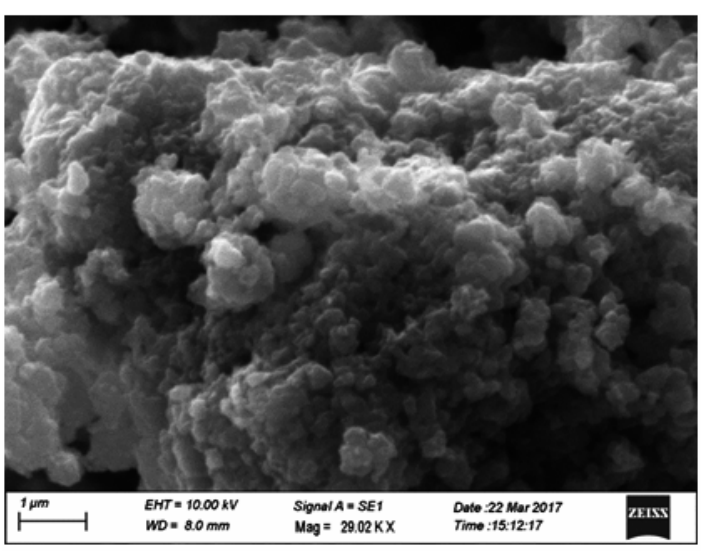

Fig. 18(a) PANI- $\mathrm{CuCl}_{2}$ Before Adsorption

\section{CONCLUSION}

All the evidences from the analysed result showed PANI-CuCl is a viable adsorbent to remove Acid Red 88 from the effluent.

\section{ACKNOWLEDGEMENT}

The authors would like to thank the are porous and irregular and smooth respectively (Fig. 18(a) \& 18(b)) which also support that the adsorbent is loaded with dye.

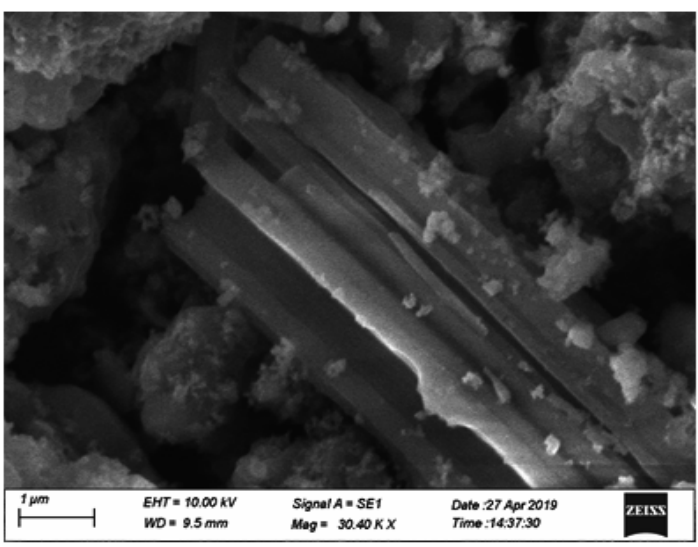

Fig. 18(b) PANI- $\mathrm{CuCl}_{2}$ After Adsorption of AR 88

Management Seethalakshmi Ramaswami college, Tiruchirappalli, TamilNadu-620002 for the encouragement and the opportunity to carry out this work.

\section{Conflict of interest}

The authors declared that there is no conflict of interest regarding the publication of this paper.

\section{REFRENCES}

1. Sekhar, C.P.; Kalidhasan, S.; Rajesh, V.; Rajesh, N. Chemosphere., 2009, 77, 842-847.

2. Mitra, M.; Ghosh, A.; Mondal, A.; Kargupta, K.; Ganguly, S.; Banerjee, D., Appl. Surf. Sci., 2017, 402, 418.

3. Baker, C.O.; Huang, X.; Nelson, W.; Kaner, R.B. Chem. Soc. Rev., 2017, 46, 1510-1525.

4. Ayad, M.; El-Hefnawy, G.; Zaghlol, S. Chem. Eng. J., 2013, 217, 460-465.

5. Ayad, M.M.; El-Nasr. A.A. J. Phys. Chem. C., 2010, 114, 14377-14383.

6. Ayad, M.M.; Abu El-Nasr, A.; Stejskal, J. J. Ind. Eng. Chem., 2012, 18, 1964-1969.

7. Bingol D.; Sevil V.; Sibel Z.; \& Utkan O.; Synthetic metals., 2012, 162, 1566-1577.

8. Aghayan.H; Mahjoub A.R;Khanchi A.R; Application surface science., 2012, 261, 14-20.

9. Pham T.D; Kobayashi.M; Adachi.Y, Polymer Science., 2015, 293, 1877-1886.

10. Yao.Y;Xu.F;Chen.M;Xu.Z;Zhu.Z; Bioresource Technology., 2010, 101, 3040-6.

11. Namasivayam, C.; Kavitha, D; Dyes Pigm., 2002, 54, 47-58.

12. Ansari.R;MohammadKhah.A;Mosayebzadeh.
Z, Annals of Biological research., 2011, 2, 323-328.

13. Wang, L.; Zhang, J.; Wang A., Desalination ., 2011, 266, 33-39.

Sarkar, K.; Banerjee, S.L.; Hydrol. Curr. Res., 2012, 3, 133.

14. Mahanta.D.; Madras.G.; Radhakrishnan.S.; Patil.S.;. Phys. Chem. B., 2009, 113, 2293-2299.

15. Bharathi K; Ramesh S; App/ Water Sci., 2013, 3, 773-790.

16. Weng CH; Lin YT; Tzeng TW; J Hazard Mater., 2009, 170, 417-424.

17. Joo JB; Park J; Yi J; J Hazard Mater., 2009, 168, 102-107.

18. Monash P; Pugazhenthi G ; Adsorption., 2009, 15, 390-405.

19. Mahmoodi NM; Khorramfar S; Najafi F; Desalination., 2011, 279, 61-68.

20. Erol Alver; Aysegül Metin ; Chem. Eng. J., 2012, 200-202, 59-67.

21. BrajaN.Patra; Muralidhar Patra; Deola Majhi; Nilaya Kumar Mohanty; Polymer science.m, 2015, 57(4), 349-354. 